\title{
Farm Size, Agricultural Mechanization and Technical Efficiency An Empirical Study on Grape Producers in China
}

\author{
Deng Lei ${ }^{1, a}$, Wang Ruimei ${ }^{1, b}$, Mu Weisong ${ }^{2, c}$, Zhao Jingjie ${ }^{3, d}$ \\ 1. College of Economics and Management, China Agriculture University, Beijing 100083, China; \\ 2. College of Information and Electrical Engineering, China Agriculture University, Beijing 100083, \\ China; \\ 3. State Administration of Taxation, Beijing Municipal Office, Beijing 100091, China \\ adeng198919@126.com, bh03109t@cau.edu.cn, cwsmu@cau.edu.cn, 'zhaojingjie006@163.com
}

Keywords: Farm size; Agricultural mechanization; Grape; Technical efficiency; Stochastic frontier analysis

\begin{abstract}
This paper attempts to examine the impact of agricultural mechanization on technical efficiency of grape producers with different farm size by using stochastic frontier analysis (SFA) approach as well as survey data of 1690 farmers in Hebei, Liaoning, Zhejiang, Shandong and Xinjiang Province. The results show that technical efficiency of grape producers in different farm size has increased significantly as the increasing of agricultural mechanization; there is a positive impact of agricultural mechanization on rural income with a small farm size while a negative impact when farm size is large. Therefore, moderate scale management should be promoted, the mode of production should be transformed and agricultural mechanization should be accelerated.
\end{abstract}

\section{Introduction}

With the development of China economy and people living standard, the demand for vegetables and fruits is increasing rapidly year by year. According to the data of population and consumption of urban and rural residents in China Statistical Yearbook, the consumption of fruits increased 33.11\%, ranging from 30.26 kilogram per capital to 40.28 kilogram per capital between 2003 and 2012. Consequently, demand for grape and its products, which are very nutritious, are expanded rapidly. This leads to a rapid development of grape industry and make grape industry become an important part of the rural economy [1]. As a traditional labor-intensive industry [2], the production of grape mainly depends on the input of land, labor and funds. With the increasing costs of production inputs and limitation access to traditional inputs, the income of farmers in China became lower and lower, which is harmful to the enthusiasm of farmers for production and is a serious barrier to the development of grape industry. Therefore, changing the mode of production, getting rid of the dependence on the traditional inputs and achieving the improvement of rural income through the technical progress and the increasing of productivity, which is not only the requirement of Chinese government to accelerate promotion of agricultural modernization and ensure the development of grape industry, but also an important driving force to the development of rural economy.

The level of agricultural mechanization is a reflection to the using status of agricultural technique and increase the input of agricultural mechanization can make a great contribution to the productivity of labor, land and fund [3]. The small-scale farmers, however, is willing to use labor instead of machines, which leads to the low input of agricultural mechanization and a single production mode. Another result from this is the low productivity and a long-term of useless of agricultural mechanization [4]. Therefore, a deep analysis on the relationship between the level of agricultural mechanization and farm size, together with the impact of agricultural mechanization on rural income and technical efficiency with different farm size is of great importance to the improvement of technical efficiency of grape production and rural income in China, and the development of grape industry. 
A large number of studies have been conducted on agricultural technical efficiency, in which the authors pay attention to three areas including the input of a specific factor, the change of environmental factors and the impact of the utilization of a new agricultural technique on production technical efficiency. Firstly, these researches mainly focus on the impact of different scale of input, social environment exercised by farmers and advances of improvement in production techniques on the technical efficiency [5]. Secondly, much attention has been paid to the estimation of the technical efficiency of a specific agricultural product [6]. The last but not the least, some authors devoted to the factors impacting on the technical efficiency [7]. Moreover, much attention has been paid to the technical efficiency of grape production including the estimation of technical efficiency and the comparison of different mode of grape production [8]. There are, however, few literatures on technical efficiency of grape production with different farm size and the relationship between the agricultural mechanization and farm size. Therefore, this paper pays attention to the change of grape technical efficiency with different farm size and agricultural mechanization based on the survey data of 1690 farmers to improve rural income, increase the enthusiasm of farmers for production and ensure the development of grape industry.

\section{Methods and data}

The data used in this paper is mainly from a fieldwork conducted by our research team in Hebei, Liaoning, Zhejiang, Shandong and Xinjiang Province, which are the major grape production areas [9]. 1690 farmers were interviewed through a face to face approach. The questionnaire mainly focuses on the physical input, input of agricultural mechanization and labors during the production of grape. Table 1 shows the distribution of samples we have interviewed.

Table 1. Distribution of sample

\begin{tabular}{ccc}
\hline Province & Sample size & $\begin{array}{c}\text { Samples account for } \\
\text { total[\%] }\end{array}$ \\
\hline Hebei & 376 & 22 \\
Liaoning & 338 & 20 \\
Zhejiang & 302 & 18 \\
Shandong & 290 & 17 \\
Xinjiang & 384 & 23 \\
Total & 1690 & 100
\end{tabular}

According to the exist studies on the technical efficiency, this paper selects the physical input, input of agricultural mechanization and labors during the production of grape as the indicators for input. Given the fact that the variety, production and farm gate prices of grape are different in different areas, and farmers pay most attention to the economic outcomes [10], according to Liu Z., et al. (2000), this paper select the sales revenue as the indicator of output. In order to distinguish the difference of areas, this paper regards the areas as dummy variables.

According to the farm size and characteristics of samples, this study divides the farmers into 9 types according to their farm size, input of agricultural mechanization (See Table 2). 
Table 2. Types of grape production

\begin{tabular}{|c|c|c|c|c|c|}
\hline Types & definition & $\begin{array}{l}\text { Farm } \\
\text { size }\left[\mathrm{m}^{2}\right]\end{array}$ & $\begin{array}{c}\text { Input of } \\
\text { mechanization }\left[\mathrm{CNY} / 667 \mathrm{~m}^{2}\right]\end{array}$ & $\begin{array}{l}\text { Sample } \\
\text { size }\end{array}$ & $\begin{array}{l}\text { Sample } \\
\text { account for } \\
\text { total[\%] }\end{array}$ \\
\hline $\mathrm{z}_{1}$ & $\begin{array}{l}\text { Small-scale with } \\
\text { low input }\end{array}$ & $<4000$ & $<100$ & 258 & 15 \\
\hline $\mathrm{z}_{2}$ & $\begin{array}{l}\text { Small-scale with } \\
\text { middle input }\end{array}$ & $<4000$ & $\geq 100$ and $<300$ & 231 & 14 \\
\hline $\mathrm{z}_{3}$ & $\begin{array}{l}\text { Small-scale with } \\
\text { high input }\end{array}$ & $<4000$ & $\geq 300$ & 188 & 11 \\
\hline $\mathrm{z}_{4}$ & $\begin{array}{l}\text { Middle-scale } \\
\text { with low input }\end{array}$ & $\begin{array}{l}\geq 4000 \text { and } \\
<13333.33\end{array}$ & $<100$ & 154 & 9 \\
\hline $\mathrm{Z}_{5}$ & $\begin{array}{l}\text { Middle-scale } \\
\text { with middle } \\
\text { input }\end{array}$ & $\begin{array}{l}\geq 4000 \text { and } \\
<13333.33\end{array}$ & $\geq 100$ and $<300$ & 218 & 13 \\
\hline $\mathrm{z}_{6}$ & $\begin{array}{c}\text { Middle-scale } \\
\text { with high input }\end{array}$ & $\begin{array}{l}\geq 4000 \text { and } \\
<13333.33 \\
\end{array}$ & $\geq 300$ & 173 & 10 \\
\hline $\mathrm{z}_{7}$ & $\begin{array}{l}\text { Large-scale with } \\
\text { low input }\end{array}$ & $\geq 13333.33$ & $<100$ & 137 & 8 \\
\hline $\mathrm{Z}_{8}$ & $\begin{array}{l}\text { Large-scale with } \\
\text { middle input }\end{array}$ & $\geq 13333.33$ & $\geq 100$ and $<300$ & 175 & 10 \\
\hline $\mathrm{Z}_{9}$ & $\begin{array}{l}\text { Large-scale with } \\
\text { high input }\end{array}$ & $\geq 13333.33$ & $\geq 300$ & 156 & 9 \\
\hline
\end{tabular}

The data showed in Table 2 implies that most farmers are small-scale, whose farm size are less than $4000 \mathrm{~m} 2$. This demonstrates that grape production system is still dominated by unorganized and dispersed farmers. On the other hand, small-scale farmers account for $47 \%$ of total low input of mechanization while the number of middle and high input of mechanization are more than that of low input of middle and large scale farmers. This is quite different from the situation of small-scale farmers, which means the level of agricultural mechanization of small-scale farmers is lower than that of middle and large scale.

Table 3 shows the information on each variety.

Table 3. Input and output of each type of farmers

\begin{tabular}{cccc}
\hline Types & Output[CNY/666.7m $\left.{ }^{2}\right]$ & $\begin{array}{c}\text { Physical } \\
\left.\text { input[CNY/666.7 }{ }^{2}\right]\end{array}$ & Labor input[CNY/666.7m $\left.{ }^{2}\right]$ \\
\hline $\mathrm{z}_{1}$ & 7400 & 1867.94 & 2620.2 \\
$\mathrm{z}_{2}$ & 8273.92 & 2323.52 & 2503.46 \\
$\mathrm{z}_{3}$ & 10702.15 & 2662.58 & 3259.59 \\
\hline $\mathrm{z}_{4}$ & 7887.21 & 1561.69 & 2350.72 \\
$\mathrm{z}_{5}$ & 9214.95 & 1653.76 & 1872.54 \\
$\mathrm{z}_{6}$ & 10231.69 & 2001.46 & 1916.86 \\
\hline $\mathrm{z}_{7}$ & 12888.42 & 1713.95 & 2042.82 \\
$\mathrm{z}_{8}$ & 12295.89 & 1773.94 & 1614.84 \\
$\mathrm{z}_{9}$ & 14554.45 & 2382.49 & 1585.1 \\
\hline
\end{tabular}

The data in Table 3 provides something interesting that the rural income increase with the increasing of farm size, which implies the increasing of farm size has a positive impact on rural income. As the increasing of level of agricultural mechanization, the production cost has been increased, which maybe result from the increasing cost of water, electricity, fertilizer and pesticide due to the utilization of agricultural machine. On the contrary, labor costs have been reduced as the increasing of level of agricultural mechanization, which implies that the use of agricultural machine will reduce the cost of labors.

\section{Methodology and model}

Most recent studies estimated technical efficiency by using Stochastic Frontier Analysis (SFA) and Data Envelopment Analysis (DEA). The latter is mainly used to estimate technical efficiency 
with multi-input and multi-output without a specific formulation. Despite its objectiveness, it seems impossible to conduct a statistical test and exclude the impact of statistical errors. SFA, however, can accurately evaluate the impact of stochastic errors and technical inefficiency on the production frontier and can analyze the factors impacting on technical efficiency. Therefore, this paper select SFA to estimate technical efficiency of grape production in China, the basic model can be defined as follow:

$\begin{array}{lllllll}\mathrm{y}_{\mathrm{i}} & = & \mathrm{x}_{\mathrm{i}} & + & \mathrm{v}_{\mathrm{i}} & - & \mathrm{u}_{\mathrm{i}}\end{array}$

$\mathrm{i}=1,2,3 \ldots, \mathrm{I}$ denotes the farmers, $\mathrm{y}_{\mathrm{i}}$ denotes the output of grape production, $\mathrm{x}_{\mathrm{i}}$ denotes the input during the production of grape, $\beta$ is the parameters, $\mathrm{v}_{\mathrm{i}}-\mathrm{u}_{\mathrm{i}}$ denotes the combined errors, $\mathrm{v}_{\mathrm{i}}$ is the stochastic errors, $\mathrm{u}_{\mathrm{i}}$ denotes the technical inefficiency, both $\mathrm{v}_{\mathrm{i}}$ and $\mathrm{u}_{\mathrm{i}}$ are independent, and $\mathrm{v}_{\mathrm{i}} \sim \mathrm{N}(0$, $\left.\sigma^{2}{ }_{\mathrm{v}}\right), \mathrm{u}_{\mathrm{i}} \sim \mathrm{N}\left(0, \sigma_{\mathrm{u}}^{2}\right)$.

According to Battese and Corra [11], we can let $\sigma^{2}=\sigma^{2}{ }_{\mathrm{v}}+\sigma_{\mathrm{u}}{ }_{\mathrm{u}}, \gamma=\sigma_{\mathrm{u}}{ }_{\mathrm{u}} /\left(\sigma^{2}{ }_{\mathrm{v}}+\sigma^{2}{ }_{\mathrm{u}}\right)$ and estimate the production function and loss function of technical efficiency, then we can get the $\beta, \delta, \sigma^{2}, \gamma$ and technical efficiency for each farmer, $\sigma^{2}$ denotes combined variance, $\gamma$ is the proportion of technical inefficiency account of combined errors. When $\gamma=0$, stochastic errors make the greatest contribution to total errors while when $\gamma=1$, technical inefficiency make the greatest contribution to total errors.

The technical efficiency of each farmer is estimated by the followed function:

$\mathrm{TE}_{\mathrm{i}}=\mathrm{E}\left(\mathrm{y}_{\mathrm{i}} \quad \mathrm{u} \quad \mathrm{u}_{\mathrm{i}}, \quad \mathrm{x}_{\mathrm{i}}\right) \quad / \quad \mathrm{E}\left(\mathrm{y}_{\mathrm{i}} \quad \mid \quad \mathrm{u}_{\mathrm{i}}=0, \quad \mathrm{x}_{\mathrm{i}}\right)$

(2)

$\mathrm{E}(\cdot)$ denotes the mathematical expect. When $\mathrm{TE}_{\mathrm{i}}=1$, there is no loss of technical efficiency, while when $\mathrm{TE}_{\mathrm{i}}<1$, the loss of technical efficiency exists.

The formulations of SFA are often set as Cobb-Douglas and trans-log production function. Given the long production lead time of grape, the production of grape is affected by current input and input in the past, and the relationship among all inputs cannot be evaluated. Therefore, this paper selects the trans-log production function as the basic model to estimate the technical efficiency of each farmer. The formulation is as follow:

$$
\text { Lny }_{\mathrm{i}}=\beta_{0}+\sum_{\mathrm{n}=1}^{4}\left(\beta_{\mathrm{n}} \mathrm{Lnx}_{\mathrm{ni}}\right)+0.5 \sum_{\mathrm{n}=1}^{4} \sum_{\mathrm{m}=1}^{4}\left(\beta_{\mathrm{nm}} \operatorname{Lnx}_{\mathrm{ni}} \mathrm{Lnx}_{\mathrm{mi}}\right)+\beta_{5} \mathrm{~d}_{1}+\beta_{6} \mathrm{~d}_{2}+\beta_{7} \mathrm{~d}_{3}+\beta_{8} \mathrm{~d}_{4}+\mathrm{v}_{\mathrm{i}}-
$$

$\mathrm{y}_{\mathrm{i}}$ denotes the sales revenue of farmers, $\mathrm{n}, \mathrm{m}=1,2,3,4$ denotes the number of inputs, $\mathrm{x}_{1}$ denotes farm size, $\mathrm{x}_{2}$ denotes the physical costs, $\mathrm{x}_{3}$ denotes the agricultural machine costs, $\mathrm{x}_{4}$ denotes the labor costs, $\mathrm{d}_{1}, \mathrm{~d}_{2}, \mathrm{~d}_{3}, \mathrm{~d}_{4}$ are dummy varieties, $\mathrm{d}_{1}=1$ denotes Hebei, $\mathrm{d}_{2}=1$ denotes Liaoning, $\mathrm{d}_{3}=1$ denotes Zhejiang, $d_{4}=1$ denotes Shandong, $d_{1}=d_{2}=d_{3}=d_{4}=1$ denotes Xinjiang.

\section{Results and discussion}

This paper estimates the production function by using Frontier 4.1 software; the results are showed in Table 4. 
Table 4. Results of stochastic frontier production function

\begin{tabular}{|c|c|c|c|c|c|c|c|c|c|}
\hline$C$ & $\frac{\mathrm{Z}_{1}}{9.2516_{* *}^{*}}$ & $\frac{\mathrm{Z}_{2}}{48.234} 7^{* * * *}$ & $\frac{\mathrm{Z}_{3}}{5.2526^{*}}$ & 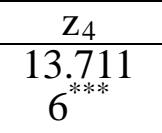 & $\frac{\mathrm{z}_{5}}{28.479} 6^{* * *}$ & $\frac{\mathrm{Z}_{6}}{-4.8785}$ & $\frac{\mathrm{z}_{7}}{19.004}$ & $\frac{\mathrm{z}_{8}}{3.9991^{*}}$ & $\frac{\mathrm{Z}_{9}}{19.2201}$ \\
\hline $\operatorname{Lnx}_{1}$ & 0.1567 & $4.1291^{*}$ & -0.5388 & -0.5714 & -1.5276 & $1.6887^{*}$ & -0.2114 & $2.3932^{\top}$ & 0.1996 \\
\hline $\operatorname{Lnx}_{2}$ & -0.1551 & -0.7608 & -0.5984 & -0.7812 & 0.6427 & -0.1450 & -1.1232 & -0.7235 & $-1.3774^{\top}$ \\
\hline $\operatorname{Lnx}_{3}$ & -1.0029 & -5.6143 & $2.0910^{*}$ & -2.8310 & -5.0036 & 2.0446 & -1.0060 & $4.3639^{*}$ & $-1.0672^{*}$ \\
\hline $\operatorname{Lnx}_{4}$ & -0.1234 & -0.0753 & -0.1901 & -0.2455 & -1.5409 & $1.4206^{\top}$ & -1.4903 & -2.0204 & $-0.6335^{*}$ \\
\hline$\left(\operatorname{Lnx}_{1}\right)^{2}$ & -0.1196 & -0.1380 & -0.1198 & -0.0413 & $0.5756^{*}$ & -0.6068 & 0.0046 & -0.0052 & -0.0039 \\
\hline$\left(\operatorname{Lnx}_{2}\right)^{2}$ & $0.0204^{\pi}$ & $0.0523^{*}$ & $0.0335^{\star}$ & $0.0405^{*}$ & -0.0526 & -0.0067 & $0.0157^{*}$ & -0.0159 & $0.0223^{*}$ \\
\hline$\left(\operatorname{Lnx}_{3}\right)^{2}$ & $0.1953^{*}$ & $1.5132^{\top}$ & -0.1893 & $0.1334^{\top}$ & $0.5019^{*}$ & 0.0452 & -0.0257 & -1.1895 & -0.0495 \\
\hline$\left(\operatorname{Lnx}_{4}\right)^{2}$ & $0.0144^{*}$ & -0.0098 & -0.0282 & -0.0532 & -0.0016 & $0.0418^{* *}$ & 0.0171 & 0.0067 & $0.0166^{*}$ \\
\hline $\begin{array}{c}\operatorname{Lnx}_{1} \operatorname{Ln} \\
x_{2}\end{array}$ & -0.0067 & -0.1912 & -0.0547 & 0.0088 & -0.2303 & $0.1974^{*}$ & -0.0297 & $0.0822^{*}$ & $0.0377^{* \pi}$ \\
\hline$\underset{x_{3}}{\operatorname{Lnx}} \operatorname{Ln}$ & $0.0436^{*}$ & -0.3872 & $0.0750^{*}$ & -0.0988 & $0.4264^{\top}$ & -0.0402 & $0.0607^{\pi}$ & $0.1510^{\top}$ & $-0.0 \underset{*}{5} 77^{*}$ \\
\hline $\begin{array}{c}\operatorname{Lnx}_{1} \operatorname{Ln} \\
\mathrm{x}_{4}\end{array}$ & 0.0231 & -0.0730 & $0.0644^{\top}$ & 0.1079 & -0.2182 & -0.0191 & $0.0474^{\top}$ & -0.4872 & 0.0039 \\
\hline $\begin{array}{c}\operatorname{Ln} x_{2} \operatorname{Ln} \\
x_{3}\end{array}$ & $0.0253^{*}$ & 0.0871 & 0.0256 & -0.0370 & -0.2404 & -0.0228 & -0.0014 & 0.1113 & $0.1734_{*}^{-\pi}$ \\
\hline $\begin{array}{c}\operatorname{Lnx}_{2} \operatorname{Ln} \\
\mathrm{x}_{4}\end{array}$ & -0.0051 & $0.0129^{*}$ & $0.0334^{\top}$ & $0.0559^{*}$ & $0.2102^{*}$ & -0.0004 & $0.1483^{\top *}$ & 0.0014 & $-0.0208^{*}$ \\
\hline $\begin{array}{c}\operatorname{Lnx}_{3} \operatorname{Ln} \\
x_{4}\end{array}$ & 0.0083 & 0.0341 & 0.0128 & $0.3724^{*}$ & 0.0933 & -0.2954 & $0.1131^{*}$ & $0.8035^{\pi}$ & $0.0940^{*}$ \\
\hline $\mathrm{d}_{1}$ & $0.1868^{\circ}$ & -0.0137 & $0.4954^{\pi}$ & $0.5460^{*}$ & $0.4984^{\pi *}$ & -0.0451 & $0.4973^{*}$ & $0.3452^{\top}$ & $0.3906^{-\pi}$ \\
\hline $\mathrm{d}_{2}$ & $0.4012^{*}$ & -0.2875 & 0.4089 & $0.8800^{\top}$ & $0.2749^{*}$ & -0.0591 & $0.8204^{\pi *}$ & -0.3369 & 0.0677 \\
\hline$d_{3}$ & $0.2068^{*}$ & -0.4301 & $0.2750^{*}$ & $0.9552^{\star}$ & $0.4943^{*}$ & $0.3595^{\star}$ & $0.2791^{\top}$ & $0.2927^{*}$ & $0.2935^{\uparrow \pi}$ \\
\hline $\mathrm{d}_{4}$ & $0.3175^{\top}$ & $0.1455^{\star}$ & $0.4706^{*}$ & $0.5189^{*}$ & $0.7814^{\top}$ & $0.3066^{*}$ & $0.7032^{\top}$ & $0.3828^{\top}$ & $0.3422^{*-\pi}$ \\
\hline$\sigma^{2}$ & $2.6277^{*}$ & $3.7956^{*}$ & $0.2011^{\top}$ & $2.0991^{\top *}$ & $2.4086^{*}$ & $1.1750^{*}$ & $1.4458^{\circ}$ & $2.9289^{*}$ & $0.5017^{* *}$ \\
\hline$\gamma$ & $0.8625^{*}$ & $0.8869^{\circ}$ & $0.8062^{\top}$ & $0.8408^{*}$ & $0.7962^{*}$ & $0.7825^{\circ}$ & $0.8713^{*}$ & $0.7987^{*}$ & $0.7836^{* *}$ \\
\hline $\begin{array}{l}\text { Log } \\
\text { Likelih } \\
\text { ood } \\
\text { functio } \\
\text { n }\end{array}$ & $\begin{array}{c}-314.36 \\
56\end{array}$ & $\begin{array}{c}-235.12 \\
00\end{array}$ & $\begin{array}{c}-403.80 \\
06\end{array}$ & $\begin{array}{c}-214.49 \\
20\end{array}$ & $\begin{array}{c}-175.91 \\
62\end{array}$ & $\begin{array}{c}-261.16 \\
16\end{array}$ & $\begin{array}{c}-271.44 \\
45\end{array}$ & $\begin{array}{c}-333.94 \\
72\end{array}$ & $\begin{array}{c}-427.01 \\
50\end{array}$ \\
\hline LR & $\begin{array}{c}64.811 \\
0^{* * *} \\
\end{array}$ & $\begin{array}{c}56.682 \\
6^{* * *} \\
\end{array}$ & $\underset{4^{* * *}}{78.794}$ & $\begin{array}{c}56.690 \\
4^{* * *}\end{array}$ & $\begin{array}{c}42.105 \\
8^{* * * *}\end{array}$ & $\begin{array}{c}61.959 \\
2^{* * *}\end{array}$ & $\begin{array}{c}54.172 \\
2^{* * *}\end{array}$ & $\begin{array}{c}47.818 \\
8^{* * *}\end{array}$ & $\underset{2^{1 * * *}}{129.393}$ \\
\hline
\end{tabular}

Note: $* 10 \%, * * 5 \%, * * * 1 \%$ significance.

Table 4 shows the parameter estimates of each type. Most estimated first-order coefficients are positive and significant across the nine models. It also shows that technical inefficiency is reducing as the farm size and input of agricultural machine increasing, which implies that the expansion of production scale and increasing of level of agricultural mechanization make a great contribution to the reduction of technical inefficiency.

Trans-log production function reflects the complex relationship among all inputs and coefficients 
are interpretable as elasticities of output evaluated at the sample mean. The formulation is as follow:

$\mathrm{T}$

(4) $\beta_{\mathrm{n}}$

$+$

$2 \beta_{\mathrm{nn}} \operatorname{Lnx}_{\mathrm{n}}$

$+$

$\sum_{\mathrm{m}=1}^{4} \beta_{\mathrm{nm}} \operatorname{Lnx} \mathrm{m}_{\mathrm{m}}$

$\mathrm{n}, \mathrm{m}=1,2,3,4$ denotes the number of input, $\mathrm{T}$ denotes the elasticity of nth input, $\beta_{\mathrm{nm}}$ denotes the coefficient of the nth and mth input. Table 5 shows the elasticity of input of agricultural machine of different types.

Table 5. Elasticity of input of agricultural machine of different types

\begin{tabular}{cc|cc|cc}
\hline Types & Elasticity & Types & Elasticity & Types & Elasticity \\
\hline $\mathrm{z}_{1}$ & 0.0381 & $\mathrm{z}_{4}$ & 0.0408 & $\mathrm{z}_{7}$ & 0.0860 \\
$\mathrm{z}_{2}$ & -0.0086 & $\mathrm{z}_{5}$ & 0.0960 & $\mathrm{z}_{8}$ & 0.1350 \\
$\mathrm{z}_{3}$ & -0.0118 & $\mathrm{z}_{6}$ & 0.0293 & $\mathrm{z}_{9}$ & 0.0360 \\
\hline
\end{tabular}

Table 5 shows that the elasticity of machine input of $\mathrm{z}_{1}$ is only $0.0381 \%$, which means if farmers of $z_{1}$ increases machine input by one percent, the output will increase by $0.0381 \%$. However, the elasticity of machine input of $z_{2}$ and $z_{3}$ is negative, which means the contribution made by machine input is reducing as the machine input increasing in small-scale types. Meanwhile, elasticities of machine input in middle and large scale types are significant positive and the elasticities in large scale types are higher than that in middle scale types, which means the productivity of agricultural machine increases significantly as production scale expansion.

Table 6 shows the technical efficiency of each farmer in different types.

Table 6. Technical efficiency of each farmer in different types

\begin{tabular}{cc|cc|cc}
\hline Types & $\begin{array}{c}\text { Technical } \\
\text { efficiency }\end{array}$ & Types & $\begin{array}{c}\text { Technical } \\
\text { efficiency }\end{array}$ & Types & $\begin{array}{c}\text { Technical } \\
\text { efficiency }\end{array}$ \\
\hline $\mathrm{z}_{1}$ & 0.7293 & $\mathrm{z}_{4}$ & 0.7494 & $\mathrm{z}_{7}$ & 0.7641 \\
$\mathrm{z}_{2}$ & 0.7091 & $\mathrm{z}_{5}$ & 0.7611 & $\mathrm{z}_{8}$ & 0.7713 \\
$\mathrm{z}_{3}$ & 0.6970 & $\mathrm{z}_{6}$ & 0.7521 & $\mathrm{z}_{9}$ & 0.7990 \\
\hline
\end{tabular}

Table 6 shows that the larger the farm size is, the higher the technical efficiency will be. The technical efficiency of small-scale farmers depressing as the level of agricultural mechanization increasing, which maybe result from the low productivity of machine due to the small farm size. On the contrary, technical efficiency of middle and large scale farmers increases as the level of agricultural mechanization increasing, which means promotion of agricultural mechanization is useful for middle and large scale farmers to increase productivities of traditional inputs such as land, labor and fund.

\section{Conclusion and implication}

This paper analyzes the impact of agricultural mechanization on technical efficiency of grape producers with different farm size, together with the relationship between level of agricultural mechanization and farm size, by using stochastic frontier analysis (SFA) approach as well as survey data of 1690 farmers in Hebei, Liaoning, Zhejiang, Shandong and Xinjiang Province in 2013. The results show that:

The impact of machine input of small-scale farmers on rural income is significant positive when machine input is low, but the impact become negative when machine input become middle and high. This implies that enlarge the machine input is a battier to the improvement of income of small-scale farmers. On the contrary, there is always a significant positive impact of machine input on income of middle and large scale farmers.

Technical efficiency increases as the production scale expanded. Meanwhile, the technical efficiency of small-scale farmers with a low machine input is higher than that of small-scale farmers with a middle and high machine input. However, technical efficiency of middle and large scale farmers increases as the level of agricultural mechanization increasing.

The results of this study show that the optimal level of agricultural mechanization is different according to the production scale of farmers. For small-scale farmers, the inadequate increasing 
machine input is a barrier to the improvement of their income. However, it is an important way to solve the problem of limit supply of traditional input and increasing costs for middle and large scale farmers to increase the level of agricultural mechanization. The further study on technical efficiency of different types shows that the expansion of production scale is meaningful and useful to increase technical efficiency. For small-scale farmers, the optimal level of productivities is achieved when the level of agricultural mechanization is low, while the increasing of level of agricultural mechanization has a significant positive impact on the technical efficiency of middle and large scale farmers. Therefore, the industrialization of grape production should be promoted and the concentration and transformation of land should be encouraged to obtain the returns to scale. Meanwhile, more attention should be paid to the acceleration of progress of agricultural mechanization and take full use of advance of technique to increase productivities, get rid of limit supply of traditional inputs, reduce production cost, achieve the improvement of rural income and ensure the development of grape industry.

\section{Acknowledgements}

China Agricultural Research System (CARS-30);

Humanities and social sciences fund of the Ministry of Education (13YJCZH182)

\section{References}

[1] A. H. Ma, Z. J. Guo and H. S. Li, et al: submitted to Journal of Hebei Agricultural Sciences (2009).

[2] D. R. Xiu and W. D. Yang: Nuisanceless Storage, Transportation and Processing of Grape (China Agriculture Press, Beijing 2007).

[3] W. H. Cao and M. L. Yang: submitted to Transactions of the Chinese Society of Agricultural Engineering (2015).

[4] B. Zhou, G. Q. Yang and J. Y. Li: submitted to Journal of Jiangxi Agricultural University (2011).

[5] J. Sauer, M. Gorton and S. Davidova: submitted to Agricultural Economics (2015).

[6] G. M. N. Islam, T. Yew and M. N. Kusairi: submitted to Trends in Applied Sciences Research (2014).

[7] Z. Liu and J. Zhuang: submitted to Journal of Comparative Economics (2000).

[8] V. H. Moreira, J. L. Troncoso and B. E. Bravo-Ureta: submitted to Ciencia e Investigacion Agraria (2011).

[9] W. S. Mu and J. Y. Feng: The Research on Economic Issues of Grape Industry in China (China Agricultural University Press, Beijing 2010).

[10] Y. Liu and J. K. Huang: submitted to Economic Research (2010).

[11] G. E. Battese and G. S. Corra: submitted to Australian Journal of Agricultural Economics (1977). 